Check for updates

Cite this: RSC Chem. Biol., 2021, 2, 1651

Received 17th November 2020, Accepted 20th August 2021

DOI: 10.1039/d0cb00209g

rsc.li/rsc-chembio

\section{Design, synthesis and evaluation of tryptophan analogues as tool compounds to study IDO1 activity $\dagger$}

\author{
Nicholas J. Cundy, (D) ${ }^{a}$ Roseanna K. Hare, ${ }^{b}$ Tina Tang, ${ }^{c}$ Andrew G. Leach, (D) ${ }^{d}$ \\ Thomas A. Jowitt, ${ }^{e}$ Omar Qureshi, ${ }^{C}$ John Gordon, ${ }^{C}$ Nicholas M. Barnes, ${ }^{c f}$ \\ Catherine A. Brady, ${ }^{\text {cf }}$ Emma L. Raven, ${ }^{9}$ Richard S. Grainger (D) *a and \\ Sam Butterworth*d
}

\begin{abstract}
The metabolism of L-tryptophan to $N$-formyl-L-kynurenine by indoleamine-2,3-dioxygenase 1 (IDO1) is thought to play a critical role in tumour-mediated immune suppression. Whilst there has been significant progress in elucidating the overall enzymatic mechanism of IDO1 and related enzymes, key aspects of the catalytic cycle remain poorly understood. Here we report the design, synthesis and biological evaluation of a series of tryptophan analogues which have the potential to intercept putative intermediates in the metabolism of 1 by IDO1. Functionally-relevant binding to IDO1 was demonstrated through enzymatic inhibition, however no IDO1-mediated metabolism of these compounds was observed. Subsequent $T_{\mathrm{m}}$-shift analysis shows the most active compound, 17, exhibits a distinct profile from known competitive IDO1 inhibitors, with docking studies supporting the hypothesis that 17 may bind at the recently-discovered $S_{i}$ site. These findings provide a start-point for development of further mechanistic probes and more potent tryptophan-based IDO1 inhibitors.
\end{abstract}

\section{Introduction}

\section{IDO1 as an oncogenic target}

Indoleamine-2,3-dioxygenase 1 (IDO1) is a heme-based dioxygenase enzyme that catalyses the oxidation of L-tryptophan 1 to $N$-formyl-L-kynurenine 2 (NFK) as the initial, rate-limiting step of the kynurenine pathway (Scheme 1). ${ }^{1-3}$ IDO1 is one of three dioxygenase enzymes: IDO1, IDO2 and TDO. Until 2007, IDO1 was referred to as IDO; subsequently, three groups

\footnotetext{
${ }^{a}$ School of Chemistry, University of Birmingham, Edgbaston, Birmingham, B15 2TT, UK. E-mail: r.s.grainger@bham.ac.uk

${ }^{b}$ Division of Infection, Immunity and Respiratory Medicine, Faculty of Biology, Medicine and Health, University of Manchester, Manchester, M13 9PL, UK

${ }^{c}$ Celentyx Ltd, Birmingham Research Park, 97 Vincent Drive, Birmingham, B15 2SQ, UK

${ }^{d}$ Division of Pharmacy and Optometry, Faculty of Biology, Medicine and Health, University of Manchester, Manchester, M13 9PL, UK.

E-mail: sam.butterworth@manchester.ac.uk

${ }^{e}$ Wellcome Trust Centre for Cell Matrix Research, Faculty of Biology, Medicine and Health, University of Manchester, Manchester, M13 9PL, UK

${ }^{f}$ Institute of Clinical Sciences, College of Medical and Dental Sciences, University of Birmingham, Edgbaston, Birmingham, B15 2TT, UK

${ }^{g}$ School of Chemistry, University of Bristol, Cantock's Close, Bristol, BS8 1TS, UK $\dagger$ Electronic supplementary information (ESI) available: IR, ${ }^{1} \mathrm{H}-\mathrm{NMR},{ }^{13} \mathrm{C}-\mathrm{NMR}$, LRMS and HRMS; UV-vis, LC-MS and MST assay data. See DOI: 10.1039/ d0cb00209g
}

independently identified a third dioxygenase, IDO2, and IDO was reclassified as IDO1. ${ }^{4-9}$

In addition to its biosynthetic function, IDO1 has been demonstrated to serve an important role in the defence against intracellular viral and bacterial infection. ${ }^{10,11}$ In the event of pathogenic invasion, IDO1 upregulation leads to a depletion of L-tryptophan 1, an essential amino acid required for the proliferation of the attacking body, and produces anti-pathogenic metabolites preventing the spread of the invading species. ${ }^{12}$ Through the modulation of L-tryptophan concentrations, IDO1 also possesses a significant immunomodulatory potential. ${ }^{13,14}$

L-Tryptophan depletion affects the ability of immune cells with tryptophan sensitive checkpoints to proliferate and initiate an immune response, with natural killer (NK) and naïve T-cells shown to be particularly sensitive to L-tryptophan starvation. $^{13,14}$ Downstream metabolites in the kynurenine

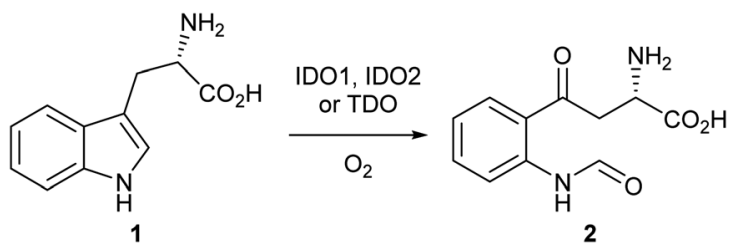

Scheme 1 Dioxygenation of L-tryptophan 1 to $\mathbf{N}$-formyl-L-kynurenine 2. 
pathway have also been implicated in IDO1's immunomodulatory potential by increasing rates of T-helper- and NK cell apoptosis. $^{15}$

In a study of 25 tumours of varying origin, 15 demonstrated consistent expression of IDO1 across individual tumour samples and a further 4 tumour types displayed $>25 \%$ IDO1 positive cells; over-expression of IDO1 in tumours is commonly associated with a poor patient prognosis. ${ }^{16-18}$ A seminal report by Van den Eynde demonstrated that inhibition of IDO1 leads to partial reversal of the immunosuppression afforded by IDO1 and significantly slowed tumour growth in mice. ${ }^{19}$ This report spurred intense investigation and discovery efforts in academic and industrial labs to find effective IDO1 inhibitors. ${ }^{20-23}$

Substrate analogue 1-methyl-1-D/L-tryptophan 3 (1-MT) was amongst the first examples of a reported IDO inhibitor. Indoximod 4 (1-methyl-1-D-typtophan), epacadostat 5 (INCB024360) and navoximod 6 (NLG919) are more recent examples of IDO1 inhibitors that have entered late stage clinical trials, however the therapeutic utility of these compounds remains to be fully established (Fig. 1). ${ }^{24-27}$

\section{IDO1 mechanism of dioxygenation}

The mechanism by which the dioxygenase family of enzymes metabolises 1 to $\mathbf{2}$ has been the subject of debate for over 60 years. $^{28}$ Hayaishi's seminal report demonstrated that in an ${ }^{18} \mathrm{O}_{2}$-enriched atmosphere, both oxygen atoms were incorporated into product $2 .^{29}$ Alongside this discovery, Hayaishi proposed a dioxetane intermediate 7 which presumably degrades to give 2 via a retro [2+2] cycloaddition (Scheme 2). Hamilton later challenged Hayaishi's dioxetane hypothesis, claiming the intermediate was too energetically strained; instead, Hamilton proposed the conversion of 1 to 2 via a Criegee-type rearrangement giving intermediate 8 (Scheme 2). ${ }^{30}$ Hayaishi's dioxetane and Hamilton's Criegee-type rearrangement intermediates, although not based on experimental evidence, remained key to many subsequent mechanistic proposals of the dioxygenase family enzymes. ${ }^{31-33}$

Sono, Stocker and Chapman individually proposed the use of a basic residue within the active site, or molecular oxygen itself, to deprotonate the indole $\mathrm{NH}$ of $\mathbf{1}$ as part of IDO1s mode of action. ${ }^{31-33}$ Chemical interrogation of this hypothesis is not evident within the literature and it falls short when one considers the $\mathrm{p} K_{\mathrm{a}}$ of the indole $\mathrm{NH}\left(\sim 16.82\right.$ in $\left.\mathrm{H}_{2} \mathrm{O}\right)$ and the lack of a sufficiently strong basic residue within the active site. ${ }^{34}$ The initial discovery of 1-MT 3 as an 'inhibitor' of IDO1 supported this theory based on its lack of an indole NH proton. ${ }^{24}$ However, later studies demonstrated that 1-MT is in fact a substrate and can be metabolised by IDO1. ${ }^{35-37}$

Since the discovery of IDO1 as an oncogenic target there has been a renewed interest in the mechanism of dioxygenation from both computational and experimental studies, with hemeintermediates of the dioxygenation being experimentally validated. ${ }^{38-44}$ Currently, IDO1 is thought to metabolise tryptophan 1 via a (A) radical or (B) electrophilic-based mechanism and involve the formation of an epoxide intermediate and a ferryl iron species (Scheme 3). ${ }^{40-45}$

\section{Design rationale}

We sought to design substrate mimics, 16-18, that have the potential to divert IDO1's dioxygenative mode of action with the hypothesis that these may be either mechanistic probes or potentially a novel class of inhibitors of IDO1 (Fig. 2).

Strategic placement of a cyclopropane in the $\alpha$-position with respect to the proposed radical centres of mimics 16 and 17 allows for a potentially rapid ring opening and diversion of potential metabolic intermediates 19 and 21, respectively (Fig. 3A and B). This mechanism of action is seen in cyclopropane containing MAO inhibitors such as tranylcypromine. ${ }^{46}$ Ring opening of 19 and 21 would result in the formation of covalently bound intermediates 20 and 22. The ring opening of

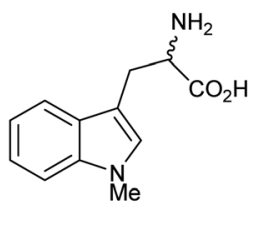

3

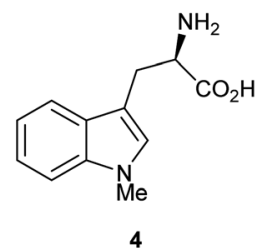

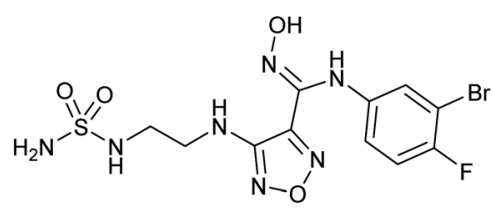

5

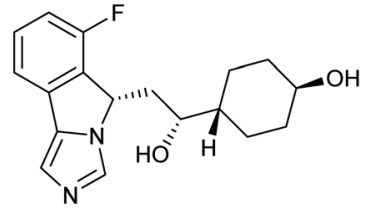

6

Fig. 1 IDO inhibitor 1-MT $\mathbf{3}$ and clinically evaluated compounds indoximod 4, epacadostat $\mathbf{5}$ and navoximod $\mathbf{6}$
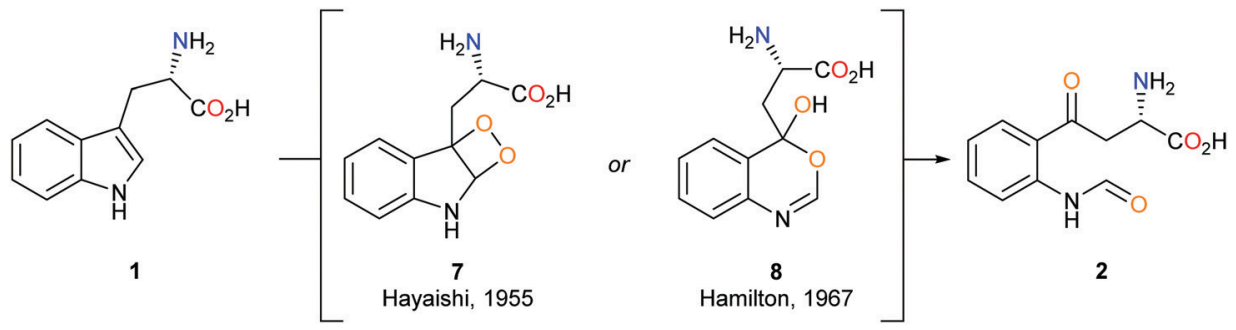

Scheme 2 Hayashi's 7 and Hamilton's 8 proposed metabolic intermediates. 


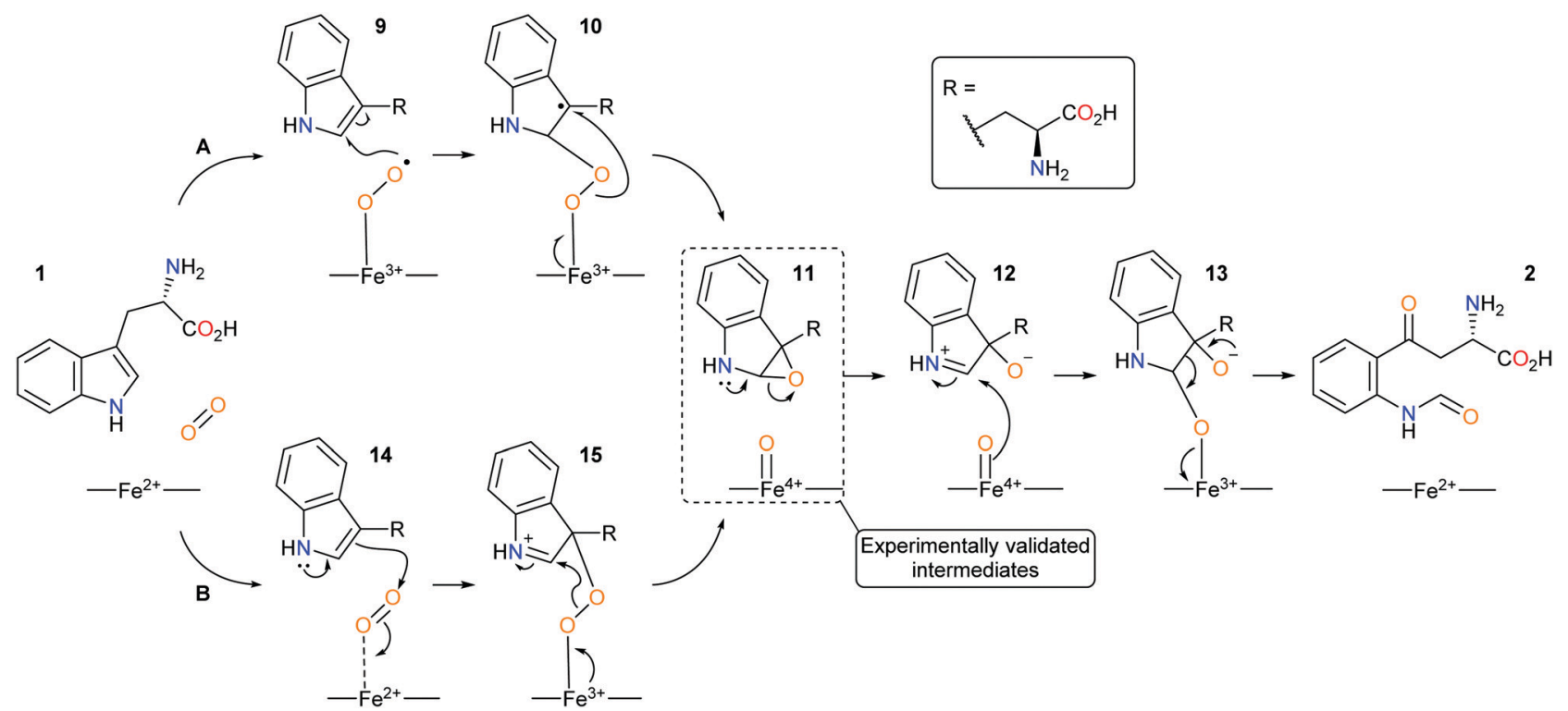

Scheme 3 Proposed new mechanistic pathways of (A) radical and (B) electrophilic IDO1 mediated dioxygenation of L-tryptophan.

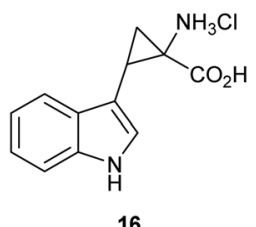

16

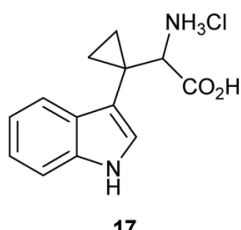

17

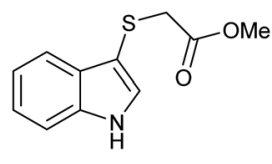

18

Fig. 2 Proposed mechanistic probes of IDO1 16-18.

19 results in the formation of stabilised captodative radical 20, giving a predicted enhancement in rate of ring opening. Further enzyme inactivation is plausible through a subsequent radical reaction with an active site residue. Compounds $\mathbf{1 6}$ and 17 were designed to explore this hypothesis, with evidence of ring-opened products or alkylated protein adducts supporting the role of radical intermediate $\mathbf{1 0}$ in the reaction mechanism.

Radical clocks have long been used in mechanistic studies to investigate radical reactivity in organic compounds with the ring opening of a cyclopropylmethyl radical being amongst the fastest known. ${ }^{4-50}$ Cyclopropanes have similarly been utilised in the mechanistic study of enzyme metabolism. Newcombe successfully designed a cyclopropane-containing substrate mimic which could discriminate between cationic and radical reactivity, based on the metabolic products, to study the mechanism of cytochrome P-450 mediated hydroxylation. ${ }^{51,52}$

Sulfenylindole 18 was designed to intercept later-stage proposed intermediates, $\mathbf{1 1}$ and $\mathbf{1 3}$, of the dioxygenation mechanism (Fig. 3C and D). We hypothesised that $\alpha$-epoxy sulfide 23 can disrupt a key metabolic intermediate via ring opening of the epoxide through neighbouring group participation to give thionium 24 and a redox inactive heme-centre. Alternatively, enzyme deactivation could be achieved through loss of a thiolate anion instead of $\mathrm{C}-\mathrm{C}$ bond cleavage during the collapse of hemithioacetal 25 resulting in covalently bound indolone 26 .

\section{Results and discussion}

The potential for $\mathbf{1 6}$ and $\mathbf{1 7}$ to act as radical traps for IDO1 is supported by docking studies of both compounds into the active site of the tryptophan-bound IDO1 structure (PDB: 5WMV). ${ }^{53}$ Tryptophan re-docks into this structure with some flexibility in the orientation of the indole, however one of the lowest energy poses has the indole in a reactive conformation, which is effectively identical to the experimentally observed pose (Fig. 4A), while both 16 and 17 demonstrate a low-energy bound pose close to that of tryptophan (Fig. 4B and C), with similar docking score to the natural substrate. In the lowest energy poses for $\mathbf{1 6}$ and $\mathbf{1 7}$ the indole is positioned in a reactive geometry relative to the heme (Fig. 4D); in this position, the cyclopropane bond that would be expected to be cleaved is sufficiently close to an ideal $90^{\circ}$ geometry, relative to the plane of the indole ring, suggesting ring-opening will be possible $\left(16,69^{\circ}\right.$ and $17,87^{\circ}-$ Fig. $\left.4 \mathrm{D}\right)$.

\section{Synthesis of $\alpha, \beta$-cyclopropyl tryptophan 16}

Literature precedent exists for the preparation of $\alpha, \beta-$ cyclopropyl tryptophan 16, however the synthesis is cumbersome and relies on hazardous, inefficient chemistry. ${ }^{54}$ To access the required cyclopropane-core, 1,2-cyclopropane amino acids were synthesised via a 1,3-dipolar cycloaddition between an amino acrylate and an in situ generated diazo species. ${ }^{5,56}$

Preliminary investigation of this route highlighted the need for an $\mathrm{N}$-protecting group on the diazo precursor for successful application of the cyclopropanation chemistry; following a screen (see ESI, $\dagger$ Appendix 3.1), Boc was found to be the optimum protecting group. To enable efficient deprotection post-cyclopropanation, amino acrylate $\mathbf{3 4}$ was prepared from $N$-Boc serine 32. The desired cyclopropane core 30 could be accessed in excellent yield and high diastereoselectivity for the 
A

19
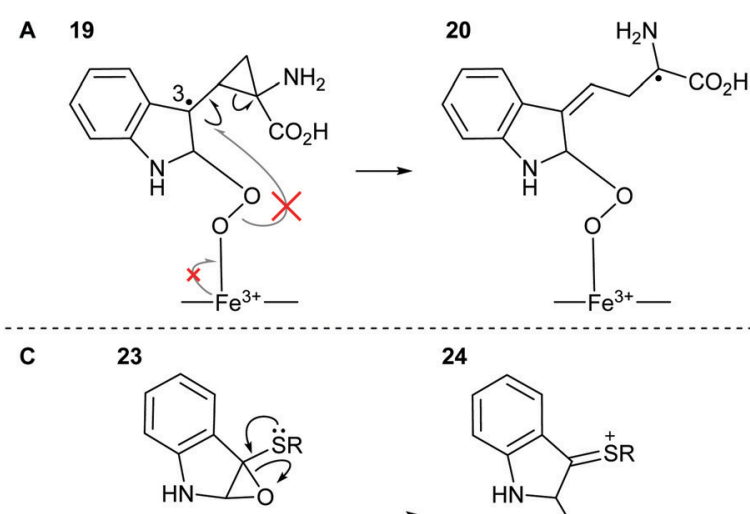

(1)
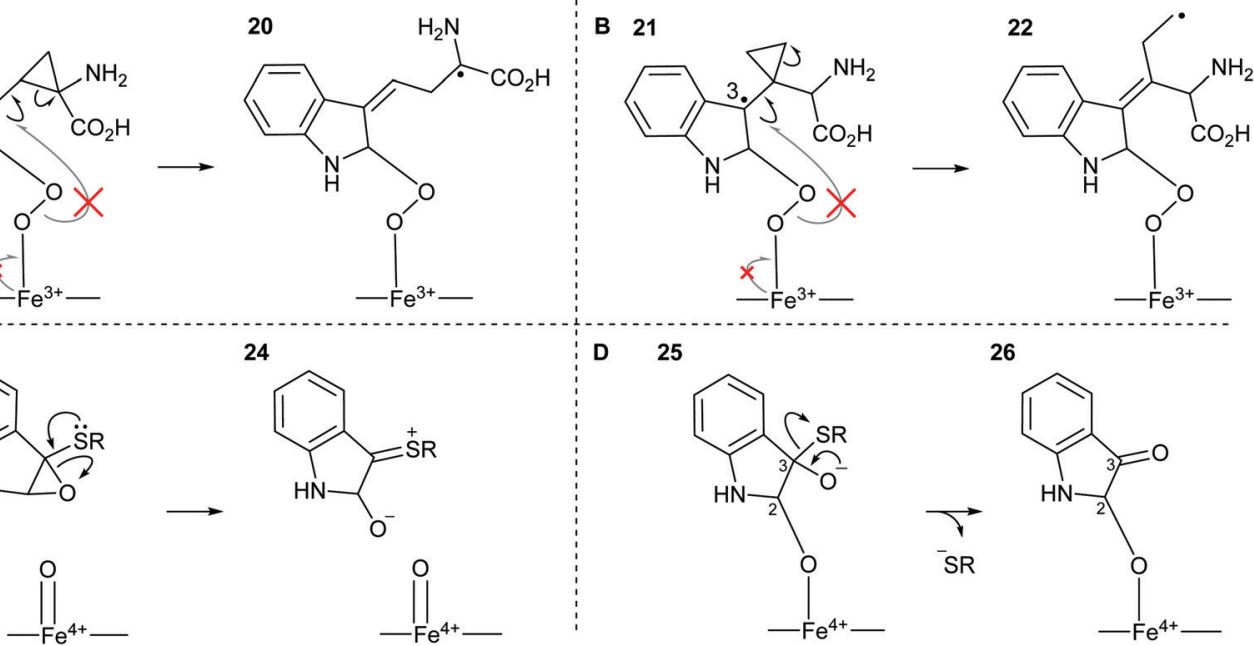

D 25
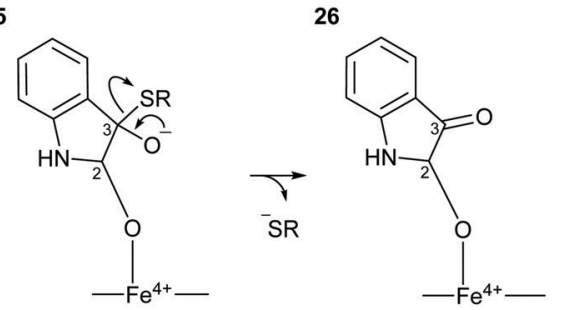

Fig. 3 (A) Radical ring opening of cyclopropane 19 giving covalently bound inhibitor complex 20 and forming a captodative radical; (B) radical ring opening of cyclopropane $\mathbf{2 1}$ giving covalently bound inhibitor complex $\mathbf{2 2}$ and a reactive radical to interact further with the protein; (C) ring opening of epoxide $\mathbf{2 3}$ via neighbouring group participation to give thionium $\mathbf{2 4}$ and a redox inactive protein; (D) loss of a thiolate anion over $\mathrm{C}-\mathrm{C}$ bond cleavage of hemi-thioacetal 25 giving covalently bound inhibitor-probe complex 26.

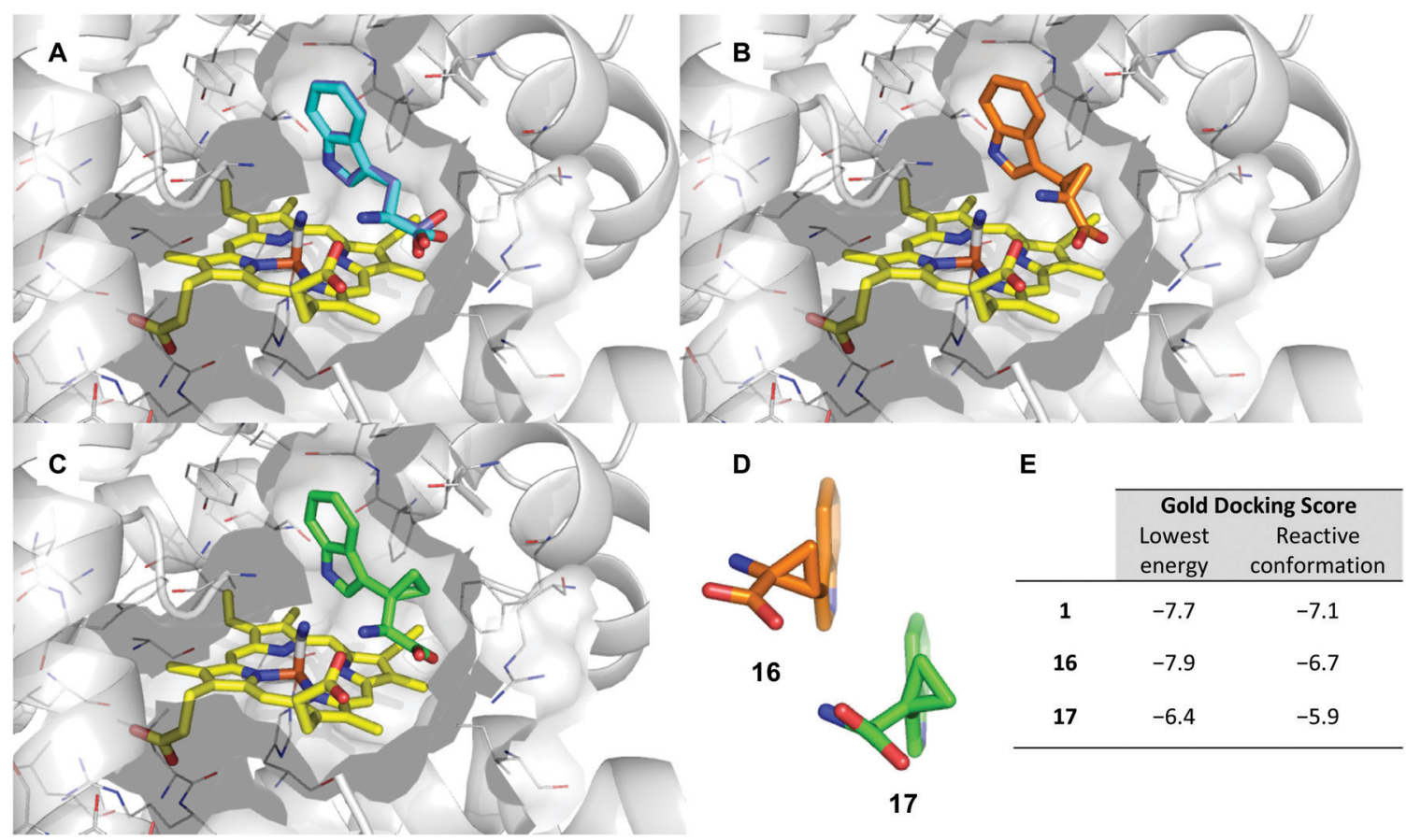

Fig. 4 Representation of the IDO1 structure 5WMV, with IDO protein residues depicted in white cartoon/lines and active site surface in white, cut to reveal the $\mathrm{CN}$-coordinated heme (yellow) and substrate binding sites; (A) experimental (cyan) and lowest energy docked (blue) pose of TRP. (B) Lowest energy docked pose of $\mathbf{1 6}$ (orange); (C) lowest energy docked pose of $\mathbf{1 7}$ (green); (D) projection of lowest energy docked poses of $\mathbf{1 6}$ and $\mathbf{1 7}$, showing the relationship between the indole ring and cyclopropane bonds; (E) gold docking scores for lowest energy pose and depicted poses with indole in a reactive conformation. Lower numbers are indicative of a more stable bound state.

$E$-isomer. Following the cyclopropanation, deprotection gave substrate mimic 16 in excellent yield over six steps (Scheme 4).

Difficulty in the isolation of pure $\mathbf{1 6}$ became apparent with the compound taking on an unexpected red colouration, despite no detectable impurities via ${ }^{1} \mathrm{H}$-NMR analysis. Subjecting substrate mimic 16 to preparative HPLC eluted the compound-containing fractions as a colourless solution, however upon concentration of the eluent the sample took on a red colouration. We hypothesised that air-oxidation of the amine adjacent to the cyclopropane could result in the radical cation which could undergo a ring-opening process. Other groups have noted the instability of aryl cyclopropyl amines under aerobic conditions - the position of the amine adjacent to the cyclopropane was identified as key for radicalbased product degradation. ${ }^{57}$ Determining the identity of the 


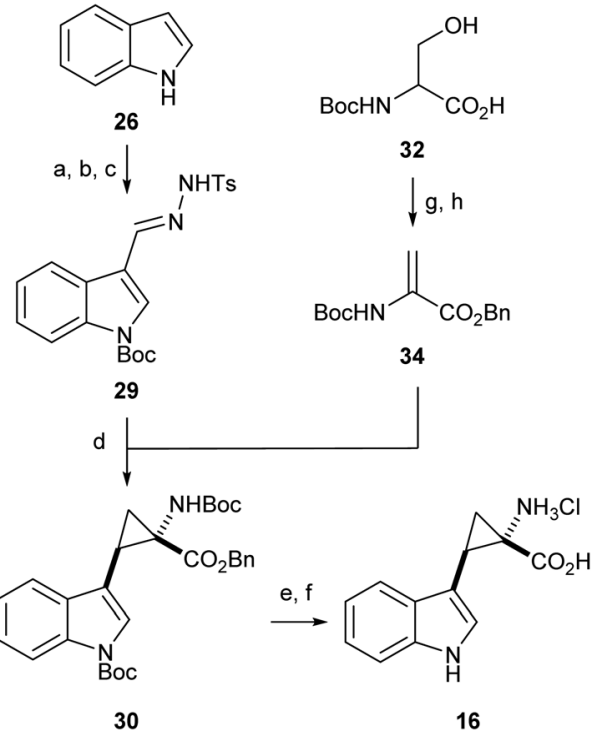

Scheme 4 Synthesis of $\alpha, \beta$-cyclopropyl tryptophan-mimic 16. (a) $\mathrm{POCl}_{3}$, DMF, $0-50{ }^{\circ} \mathrm{C}, 2.5 \mathrm{~h}, 91 \%$ (27); (b) (Boc) ${ }_{2} \mathrm{O}, \mathrm{Et}_{3} \mathrm{~N}, \mathrm{DMAP}, \mathrm{CH}_{2} \mathrm{Cl}_{2}, 23{ }^{\circ} \mathrm{C}$, $18 \mathrm{~h}, 99 \%$ (28); (c) $\mathrm{TsNHNH}_{2}, \mathrm{MeOH}, 50{ }^{\circ} \mathrm{C}, 4 \mathrm{~h}, 99 \%$ (29); (d) (i) 29, $\mathrm{Cs}_{2} \mathrm{CO}_{3}$, BTAC, Dry PhMe $23{ }^{\circ} \mathrm{C}, 1.5 \mathrm{~h}$, (ii) 34, $90{ }^{\circ} \mathrm{C}, 16 \mathrm{~h}, 91 \%$ (92:8, E:Z) (30); (e) $10 \% \mathrm{Pd} / \mathrm{C}, \mathrm{MeOH}, 23{ }^{\circ} \mathrm{C}, 0.75 \mathrm{~h}, 94 \%$ (31); (f) $4 \mathrm{M} \mathrm{HCl}$ in 1,4-dioxane, $23{ }^{\circ} \mathrm{C}, 23 \mathrm{~h}, 99 \%$ (16); (g) 32, $\mathrm{Cs}_{2} \mathrm{CO}_{3}, \mathrm{DMF}, 23{ }^{\circ} \mathrm{C}, 0.3 \mathrm{~h}$, (ii) $\mathrm{BnBr}, 23{ }^{\circ} \mathrm{C}$, $17.5 \mathrm{~h}, 78 \%$ (33); (h) (i) $\mathrm{MsCl}, \mathrm{DMAP}, 0{ }^{\circ} \mathrm{C}, 0.25 \mathrm{~h}$, (ii) $\mathrm{Et}_{3} \mathrm{~N}, 0-23{ }^{\circ} \mathrm{C}, 16.5 \mathrm{~h}$, $83 \%(34)$.

degradation product was beyond the scope of the investigation and the sample was taken forward and subjected to biochemical evaluation.

\section{Synthesis of $\beta, \beta^{\prime}$-cyclopropyl tryptophan 17}

Synthesis of $\beta, \beta^{\prime}$-cyclopropyl tryptophan substrate mimic 17 required the cyclodialkylation of 3-indole acetonitrile 35 to install the desired spirocyclic cyclopropane. Repetition of reported literature conditions failed to provide a productive outcome; ${ }^{58}$ judicious choice of di-halo ethane derivative and addition rate of LDA proved key to the success of the reaction and cyclopropyl nitrile 36 was accessed in excellent yield (see ESI, $\dagger$ Appendix 3.2). Subsequent DIBAL-H mediated reduction of nitrile 36 followed by a Strecker reaction of the resulting aldehyde 37 afforded 17 in moderate yield as the hydrochloride salt (Scheme 5). ${ }^{58,59}$ Inhibitor 17 was designed to overcome what was perceived to be the root of the instability of inhibitor 16: the presence of an amine directly attached to the cyclopropane. Upon isolation, inhibitor $\mathbf{1 7}$ proved to be stable to aerobic conditions.

\section{Synthesis of sulfenylindole 18}

Sulfenylindole 18 was readily prepared in a single step via an iodine-mediated sulfylation of indole, accessing the desired material is excellent yield (Scheme 6). ${ }^{60}$

\section{Biochemical evaluation}

Compounds 16-18 were evaluated against recombinant human IDO1 mutant F164A. The F164A mutant represents a minor
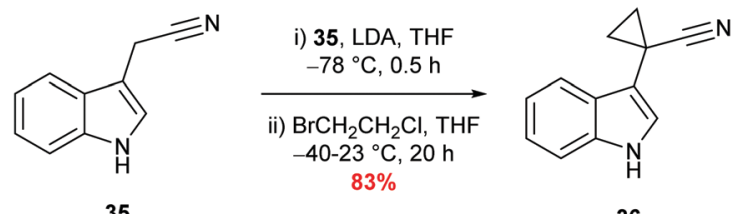

35

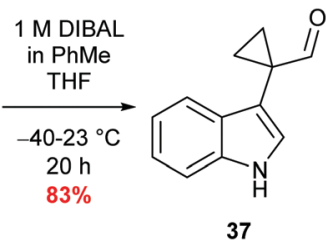

i) $\mathrm{NaCN}, \mathrm{NH}_{4} \mathrm{C}$ $7 \mathrm{~N} \mathrm{NH}_{3}$ in $\mathrm{MeOH}$ $\frac{0-50{ }^{\circ} \mathrm{C}, 18.5 \mathrm{~h}}{\text { ii) } 9 \mathrm{M} \mathrm{HCl}_{(\mathrm{aq})}}$ Reflux, $6 \mathrm{~h}$ $48 \%$

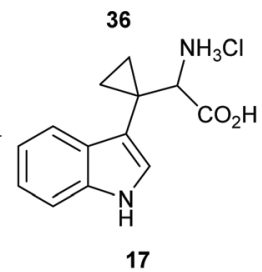

Scheme 5 Synthesis of $\beta, \beta^{\prime}$-cyclopropyl tryptophan-mimic 17

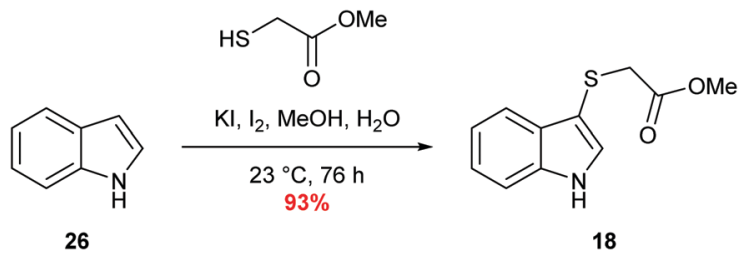

Scheme 6 Synthesis of sulfenylindole 18

structural change in the active site topology with a $\sim 5$-fold and 30 -fold drop in $K_{\mathrm{d}}$ and $K_{\mathrm{m}}$, with respect to 1, when compared to wtIDO1. ${ }^{53}$ Importantly the F164A $k_{\text {cat. }}$ is comparable to wtIDO1 and, as a result, IDO1 F164A was deemed an appropriate mutant for mechanistic investigations. ${ }^{61}$

\section{LC-MS-based detection kinetic assay}

To determine whether our compounds were metabolised by IDO1, we incubated IDO1 and substrate mimics 16-18 and analysed the post-assay media via LC-MS to detect any metabolic by-products. We hypothesised plausible metabolic byproducts for 16 (38-41, Scheme 7), 17 (41-43, Scheme 7 below) and 18 (45-51, Scheme 8) and analysed the assay media for their presence (see ESI, $\dagger$ Appendix 3.3).

Our control experiments demonstrated clear turnover of $\mathbf{1}$ and $\mathbf{3}$ (see ESI, $\dagger$ Appendix 3.4) to their respective dioxygenated metabolites. When subjecting substrate mimics 16 or 17 to the assay, no masses corresponding to plausible metabolic products were observed (see ESI, $\dagger$ Appendix 3.5 and 3.6). One possible explanation for the lack of observed turnover is the lack of substrate mimic recognition by IDO1, while another could be that the substrate mimics are partially metabolised but effective inhibition is taking place and is inactivating IDO1 to further compound turnover.

Analysis of the metabolites of substrate mimic 18 identified a mass corresponding to the radical cation of peroxy intermediate 45 or thioester 47 (see ESI, $\dagger$ Appendix 3.7). A mass corresponding to deprotonated enol 46 or epoxide 49 (see ESI, $\dagger$ Appendix 3.8) was also observed. Alternatively, the observed masses could be a result of mono- or dioxidation of sulfide 18 to sulfoxide $\mathbf{5 0}$ or sulfone $\mathbf{5 1}$ (Scheme 8).

Due to a lack of convincing enzymatic turnover we sought to assess the binding of our compounds to IDO1 using both inhibition and $T_{\mathrm{m}}$ shift assays. 
A<smiles>NC1(C(=O)O)CC1c1c[nH]c2ccccc12</smiles>

Electrophilic mech.

$M_{w}=216.2$

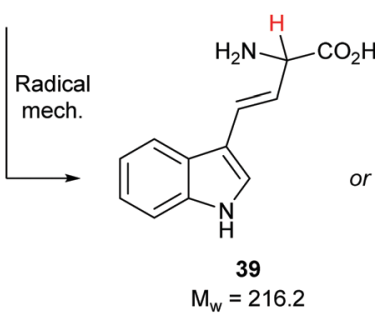

or

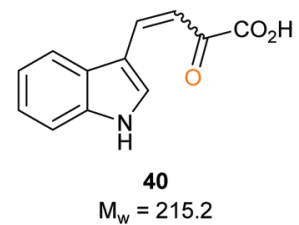

B<smiles>NC(C(=O)O)C1(c2c[nH]c3ccccc23)CC1</smiles>

$\mathrm{M}_{\mathrm{w}}=230.3$

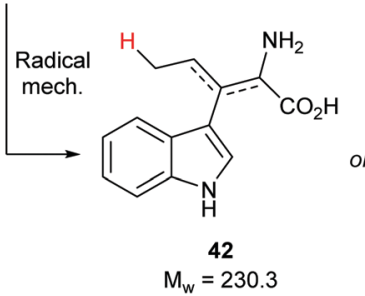

or
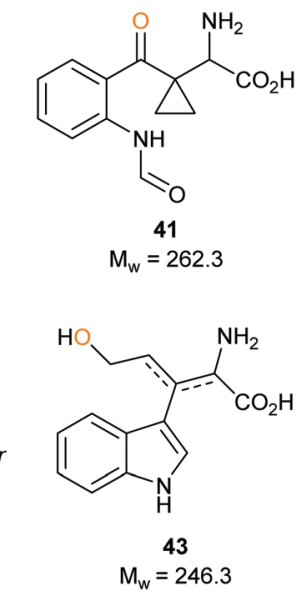

Scheme 7 Plausible metabolic by-products of IDO1 mediated dioxygenation of tryptophan-mimics (A) 16 and (B) 17

\section{IDO1 inhibition assay}

To understand the effects of compounds 16-18 on IDO1 they were pre-incubated with the active protein $(5 \mu \mathrm{M})$ for 15 minutes (see ESI, $\dagger$ Appendix 3.8) prior to the addition of 1, with the formation of 2 (abs. $=321 \mathrm{~nm}$ ) followed by UV-vis spectroscopy. A reduction in the rate of formation of 2 versus the control was interpreted as inhibition of IDO1, with epacadostat 5 used as the positive control (Fig. 5).

Under these conditions high concentrations $(1 \mathrm{mM})$ of 16-18 resulted in inhibition of IDO1 mediated production of 2. Reducing the dosed concentration of compound $\mathbf{1 6}$ saw a rapid loss in IDO1 inhibitory activity with the level of inhibition returning to control levels when dosed at $100 \mu \mathrm{M}$. Dosing compound 18 at $100 \mu \mathrm{M}$ led to a minor alleviation in the inhibition afforded by the substrate mimic. Reduced detection of 2 in the inhibition experiments could therefore be a result of 18 acting as a competitive substrate. Inhibition studies of compound 17 however highlighted a significant reduction in levels of 2 at concentrations as low as $10 \mu \mathrm{M}$.

We developed two further assays to interrogate any timedependency in substrate mimic 17's inhibitory action or the inability of compound $\mathbf{1 7}$ to be outcompeted by its natural substrate: key characteristics of an uncompetitive inhibition mechanism (Fig. 5). Co-administering 17 and 1 simultaneously led to an initial increase in the NFK produced, albeit at a reduced rate compared to the control, but after a period of 15 min the signal plateaued. To determine whether the 17 could be outcompeted, after a 15 min pre-incubation period of IDO1 and $17,1(10 \mathrm{mM})$ was introduced and the production of 2 was followed. No observation of additional 2 was observed suggesting 17 was not outcompeted by a higher concentration of Trp. Together, the data are suggestive of an uncompetitive inhibition mechanism. It is known that some classes of IDO1 inhibitors act by stabilising the heme-free apo state of the enzyme, which can be detected by loss of the characteristic IDO1-heme absorption band at $405 \mathrm{~nm}$. No such change is observed on incubating 17 with IDO1, ruling out this mechanism of inhibition (see ESI, $\dagger$ Appendix 3.9). ${ }^{62}$

\section{Thermal shift assay}

Binding events between a ligand and a protein typically result in a stabilising interaction which is manifested in an altered melting point or $T_{\mathrm{m}}$ value, and this approach is now a widely accepted method of establishing protein-ligand interactions. ${ }^{63,64}$ In order to determine whether there is a binding event between

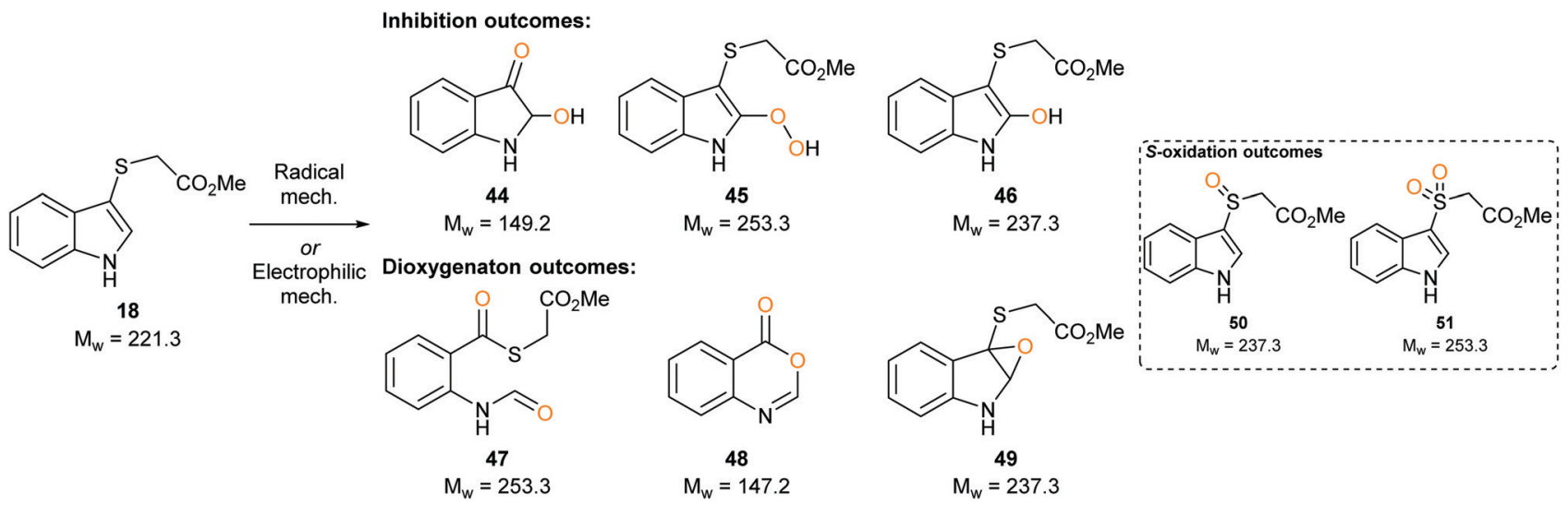

Scheme 8 Plausible metabolic by-products of IDO1 mediated dioxygenation of sulfenylindole 18 metabolism. 

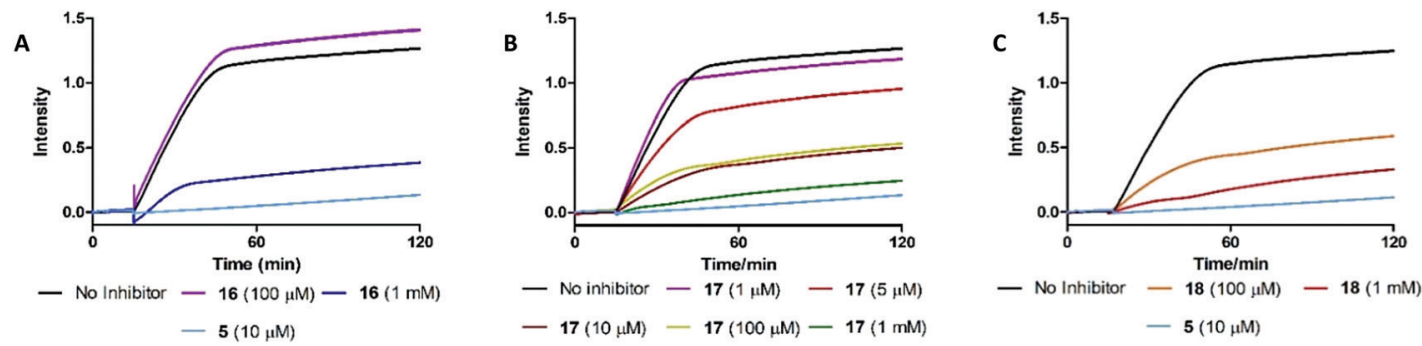

$-17(10 \mu \mathrm{M})-17(100 \mu \mathrm{M})-17(1 \mathrm{mM})$

$-5(10 \mu \mathrm{M})$
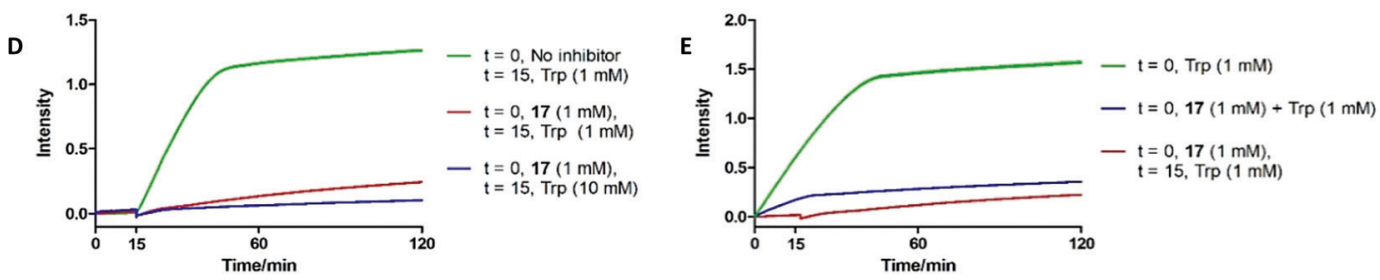

Fig. 5 UV-based inhibition assay data for substrate mimics (A) 16, (B) 17 and (C) 18. (D) Out-competition and (E) co-incubation data for substrate mimic 17.

IDO1 and 17, we subjected compound 17 to thermal shift analysis using 1-MT 3 and epacadostat 5 as positive controls for a binding interaction.

Control experiments identified that at low IDO1:SYPRO (fluorescent dye) dilution ratios the protein was not stable, demonstrating a $T_{\mathrm{m}} \sim 30{ }^{\circ} \mathrm{C}$ (Fig. 6). Increasing the IDO1: SYPRO dilution factor ratio gave a stable $T_{\mathrm{m}}$ value. Interestingly, we observed a change in fluorescence even in the absence of the SYPRO dye. As the instrument used utilises non-specific blue LED excitation $(\sim 400-450 \mathrm{~nm})$ which corresponds to the IDO-heme absorption band, we hypothesised that the fluorescence is a result of the release of fluorescent porphyrin from the heme-based enzyme upon heating.

Initial evaluation of the IDO1 $T_{\mathrm{m}}$ values in the presence of epacadostat $\mathbf{5}$ or $\mathbf{1 7}$ were performed in the presence of SYPRO dye (Fig. 7). We observed a significant shift in the $T_{\mathrm{m}}$ value when IDO1 and $\mathbf{5}$ were incubated, corresponding to a significant binding event as would be expected for this high affinity ligand. Unfortunately, when IDO1 and 1-MT 3 or cyclopropane

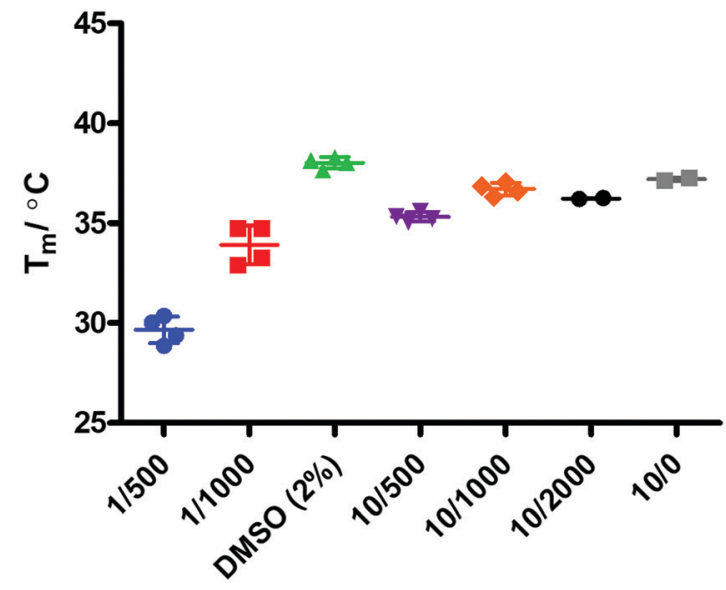

Fig. 6 Controls - [IDO] $\mu$ M/SYPRO dye dilution factor.

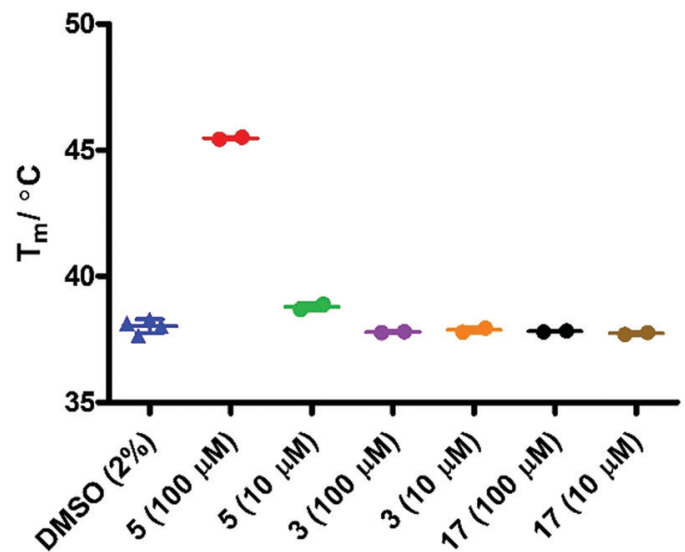

Fig. $7 T_{m}$ analysis in the presence of SYPRO dye (1/2000).

17 were incubated no shift in the protein $T_{\mathrm{m}}$ value was observed. The weak signal at lower concentrations of $\mathbf{5}$ and absence of shift for 3 suggest that the $T_{\mathrm{m}}$ of IDO is not sensitive to weaker ligands under these conditions.

In order to assess if removing SYPRO and following the change in heme signal alone would provide a more sensitive experiment, the experiment was replicated in the absence of the SYPRO dye and with higher concentrations of 3 and $\mathbf{1 7 .}$ Surprisingly this resulted in a significant change to the outcome of the experiment (Fig. 8). Incubation of IDO1 and epacadostat 5 or 1-MT 3 resulted in no change in the observed $T_{\mathrm{m}}$ value, whereas incubation of IDO1 and $\mathbf{1 7}$ saw a significant change in the $T_{\mathrm{m}}$ value at higher concentration. The conflicting data in these two experiments may be rationalised when considering the origin of the fluorescence. The SYPRO dye model changes in fluorescence as a result of the global change in the protein structure and the dye binding to the newly exposed hydrophobic surfaces. It would be expected that high affinity ligands with multiple binding interactions could afford significant 


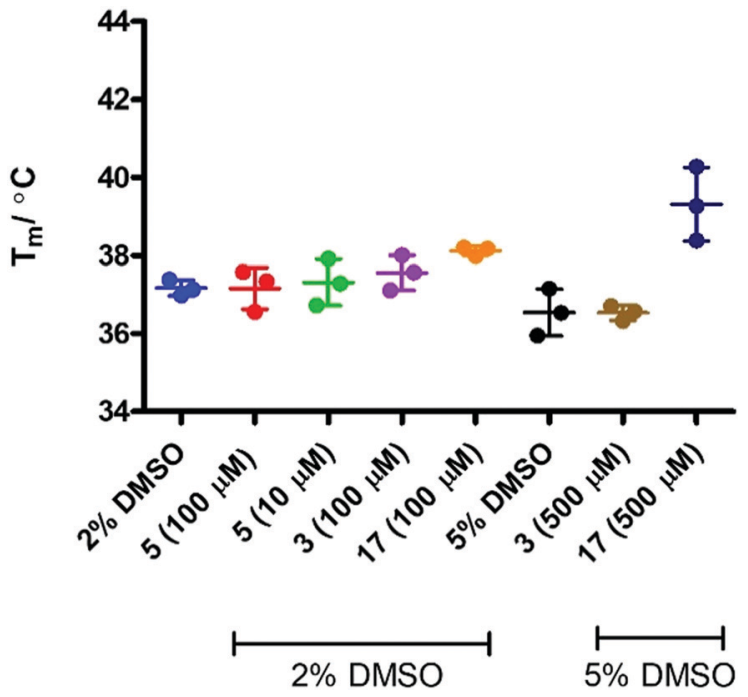

Fig. $8 T_{m}$ analysis in the absence of SYPRO dye.

stabilisation to an overall protein structure. In the absence of SYPRO, the fluorescence gain is a result of heme-environment changes alone suggesting any changes in $T_{\mathrm{m}}$ under these experimental parameters result from stabilisation of the region of the protein that binds the heme group.

X-ray co-crystallographic studies of $\mathbf{5}$ have highlighted significant active site pocket interactions which could feasibly contribute to increased protein stability as observed in SYPROcontaining $T_{\mathrm{m}}$ assays. $^{52}$

As the use of direct detection of IDO $T_{\mathrm{m}}$ is a novel assay format we sought an alternative biophysical method for the detection of the interaction between 17 and IDO-1. As seen in Fig. 9, this interaction can be detected by Microscale thermophoresis (MST) using labelled IDO1, with 17 demonstrating a $K_{\mathrm{d}}$ of $35 \mu \mathrm{M}$ which is consistent with the inhibition data observed previously (Fig. 5b). Interestingly neither 1 nor 3 provide a significant signal in this model (see ESI, $\dagger$ Appendix 3.10), providing further evidence that $\mathbf{1 7}$ has a novel interaction/inhibition mechanism.

A 2017 study identified a secondary binding site of IDO1 $\left(\mathrm{S}_{\mathrm{i}}\right)$ which, when bound, inhibits turnover of $1 .^{52}$ It was demonstrated

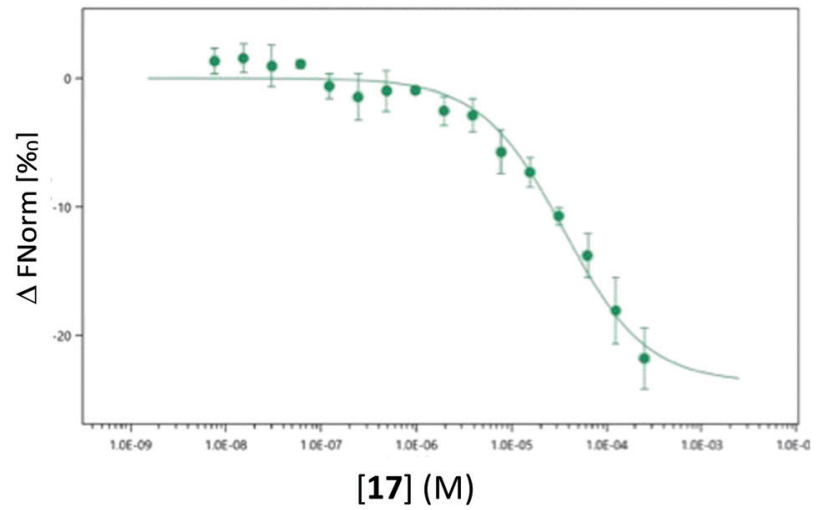

Fig. 9 Microscale thermophoresis (MST) analysis of the dose-dependent interaction between 17 and IDO1, $K_{d} 35.0 \mu \mathrm{M} \pm 6.96 \mu \mathrm{M}$.
Table 1 Gold docking scores for S vs. Si site for TRP and 17

\begin{tabular}{llll}
\hline \multicolumn{4}{l}{ Gold docking score } \\
\cline { 2 - 4 } & S site lowest & $\mathrm{S}_{\mathrm{i}}$ site lowest & $\mathrm{S}_{\mathrm{i}}$ site shown \\
\hline $\mathbf{1}$ & -7.7 & -7.2 & -7.0 \\
$\mathbf{1 7}$ & -6.4 & -7.0 & -6.4
\end{tabular}

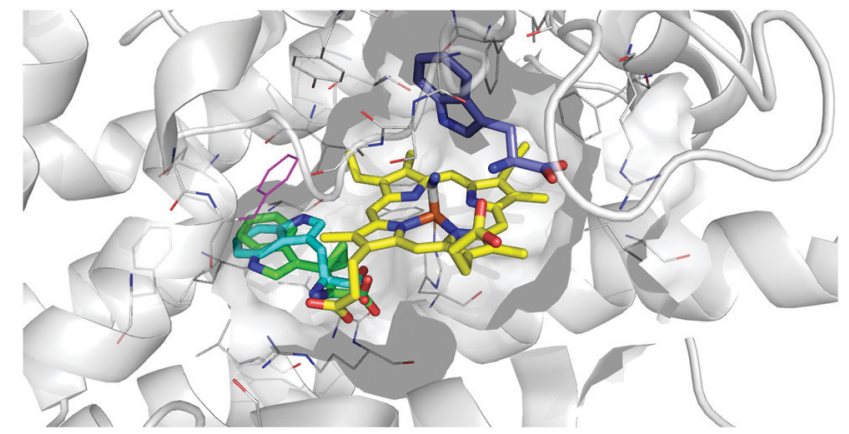

Fig. 10 Representation of the IDO1 structure 5MWV, with IDO protein residues depicted in white cartoon/lines and active site surface in white, cut to reveal the $\mathrm{CN}$-coordinated heme (yellow) and substrate binding sites. Docked pose of tryptophan at the $\mathrm{S}$ site (blue) and $\mathrm{S}_{\mathrm{i}}$ site (cyan) are overlaid with 17 (green), with F270 which moves to form the Si site depicted in magenta.

that at high concentrations of 1, IDO1 was significantly inhibited by its natural substrate through suspected binding to the $S_{i}$ site subsequent crystallographic data identified inhibitors bound to the proximal-side of the heme-centre, effecting inhibition via an altered active site topology. Based on binding to the $S_{i}$ site, substrate mimic $\mathbf{1 7}$ is not predicted to have stabilising active site pocket interactions, but it is predicted to have a significant interaction with the heme-centre.

Given the data demonstrating a mode of inhibition of $\mathbf{1 7}$ that is clearly distinct from the control inhibitors tested, we then considered the possibility that $\mathbf{1 7}$ may act by binding at this site. Docking of $\mathbf{1 7}$ into the $\mathrm{S}_{\mathrm{i}}$ site suggests the cyclopropane ring would be tolerated, with the key interactions made by TRP retained and docking scores comparable between tryptophan and 17, as well as $\mathbf{1 7}$ at the $\mathrm{S}$ site (Table 1 and Fig. 10).

\section{Conclusions}

A series of IDO1 mechanistic probes 16-18 were designed based on putative intermediates in the IDO1-mediated metabolism of L-tryptophan, with docking studies supporting their potential to interact with IDO1 with a tryptophan-like binding pose. These compounds were successfully synthesised and characterised, however $\alpha, \beta$-cyclopropyl tryptophan 16 showed unexpected instability which limited its use in subsequent biological studies.

Incubation of compounds 16-18 with IDO1 did not result in the observation of established epoxide or di-carbonyl metabolites, however there was also no evidence of metabolites by diversion of putative enzymatic intermediates. Given 16-18 are 
able to inhibit IDO1-mediated metabolism of L-tryptophan these results suggest compounds 16-18 do not act as simple active-site substrate mimics and therefore our findings do not provide further clarification of the IDO1 mechanism.

More detailed studies on the inhibitory activity of $\beta, \beta^{\prime}$ cyclopropyl tryptophan 17 demonstrated an uncompetitive inhibition mechanism. $T_{\mathrm{m}}$ studies on IDO1 incubated with epacadostat 5 detected denaturation using the fluorescent dye SYPRO, showing clear stabilisation of the protein which is not replicated by $\mathbf{1 7}$. However it was also observed that the denaturation of IDO1 can be directly monitored under dye-free conditions based on change in heme fluorescence. In this experimental set up $\mathbf{1 7}$ shows a significant temperature shift, consistent with stabilisation of the heme environment independent of overall protein folding. Our UV-data demonstrated that co-incubation of IDO1 and $\mathbf{1 7}$ did not displace heme and an orthogonal MST assay confirmed that target engagement with inhibitor 17 could be achieved. The lack of target engagement of known active site ligands, 1 or 3, in further MST assays strongly suggests that $\mathbf{1 7}$ adopts a distinct binding mode from active site ( $\mathrm{S}$ site) ligands. These findings, alongside the evidence of uncompetitive inhibition, led to the hypothesis that $\mathbf{1 7}$ binds at the recently-discovered $S_{i}$ site, which is supported by subsequent docking studies.

\section{Author contributions}

NJC, RH, TT, AGL, OQ, JG, NMB, CAB, ER, RSG and SB designed the research, analysed data and reviewed and approved the final manuscript. NJC performed the synthesis, carried out the LC-MS and IDO1 inhibition assays and co-wrote the manuscript with RSG and SB. RH conducted $T_{\mathrm{m}}$ assays, TAJ performed the MST assays, SB conducted the heme-UV assays and TT verified IDO1 activity. AGL conducted molecular docking.

\section{Conflicts of interest}

NJC was a PhD student sponsored by Celentyx Ltd. TT, OQ, CAB are employees of Celentyx Ltd with share options in the company. JG and NMB are Directors of Celentyx Ltd with shareholdings in the company. There are no other conflicts to declare.

\section{Acknowledgements}

The authors would like to thank Dr C S Le Duff, Dr C W Tsang and Dr P Ashton for analytical support and Celentyx Ltd and EPSRC (EP/N509590/1) for funding (CASE award to NJC).

\section{Notes and references}

1 Y. Kotake, Hoppe-Seyler's Z. Physiol. Chem., 1936, 243, 237-265.

2 C. Itagaki and Y. Nakayama, Hoppe-Seyler's Z. Physiol. Chem., 1941, 270, 83-88.
3 O. Hayaishi and R. Y. Stanier, J. Bacteriol., 1951, 62, 691-709.

4 S. Yamamoto and O. Hayaishi, J. Biol. Chem., 1967, 242, 5260-5266.

5 F. Hirata, O. Hayaishi, T. Tokuyama and S. Senoh, J. Biol. Chem., 1974, 249, 1311-1313.

6 O. Hayaishi, Acta Vitaminol. Enzymol., 1975, 29, 17-20.

7 R. Metz, J. B. Duhadaway, U. Kamasani, L. Laury-Kleintop, A. J. Muller and G. C. Prendergast, Cancer Res., 2007, 67, 7082-7087.

8 H. J. Yuasa, M. Takubo, A. Takahashi, T. Hasegawa, H. Noma and T. Suzuki, J. Mol. Evol., 2007, 65, 705-714.

9 H. J. Ball, A. Sanchez-Perez, S. Weiser, C. J. Austin, F. Astelbauer, J. Miu, J. A. McQuillan, R. Stocker, L. S. Jermiin and N. H. Hunt, Gene, 2007, 396, 203-213.

10 R. Yoshida, Y. Urade, M. Tokuda and O. Hayaishi, Proc. Natl. Acad. Sci. U. S. A., 1979, 76, 4084-4086.

11 R. Yoshida and O. Hayaishi, Proc. Natl. Acad. Sci. U. S. A., 1978, 75, 3998-4000.

12 S. V. Schmidt and J. L. Schultze, Front. Immunol., 2014, $5,384$.

13 D. H. Munn, E. Shafizadeh, J. T. Attwood, I. Bondarev, A. Pashine and A. L. Mellor, J. Exp. Med., 1999, 189, 1363-1372.

14 G. K. Lee, H. J. Park, M. Macleod, P. Chandler, D. H. Munn and A. L. Mellor, Immunology, 2002, 107, 452-460.

15 G. Frumento, R. Rotondo, M. Tonetti, G. Damonte, U. Benatti and G. B. Ferrara, J. Exp. Med., 2002, 196, 459-468.

16 M. Platten, W. Wick and B. J. Van den Eynde, Cancer Res., 2012, 72, 5435-5440.

17 L. Hornyák, N. Dobos, G. Koncz, Z. Karányi, D. Páll, Z. Szabó, G. Halmos and L. Székvölgyi, Front. Immunol., 2018, 9, 151.

18 L. Brochez, I. Chevolet and V. Kruse, Eur. J. Cancer, 2017, 76, 167-182.

19 C. Uyttenhove, L. Pilotte, I. Theate, V. Stroobant, D. Colau, N. Parmentier, T. Boon and B. J. Van den Eynde, Nat. Med., 2003, 9, 1269-1274.

20 U. F. Röhrig, S. R. Majjigapu, P. Vogel, V. Zoete and O. Michielin, J. Med. Chem., 2015, 58, 9421-9437.

21 G. C. Prendergast, W. P. Malachowski, J. B. DuHadaway and A. J. Muller, Cancer Res., 2017, 77, 6795-6811.

22 J. E. Cheong, A. Ekkati and L. Sun, Expert Opin. Ther. Pat., 2018, 28, 317-330.

23 B. J. van den Eynde, N. van Baren and J.-F. Baurain, Annu. Rev. Cancer Biol., 2020, 4, 241-256.

24 S. G. Cady and M. Sono, Arch. Biochem. Biophys., 1991, 291, 326-333.

25 E. Soliman, T. Neuger, E. C. Dees, R. D. Harvey, H. Han, R. Ismail-Khan, S. Minton, N. N. Vahanian, C. Link, D. M. Sullivan and S. Antonia, Oncotarget, 2014, 5, 8136-8146.

26 C. Jochems, M. Fantini, R. I. Fernando, A. R. Kwilas, R. N. Donahue, L. M. Lepone, I. Grenga, Y. S. Kim, M. W. Brechbiel, J. L. Gulley, R. A. Madan, C. R. Heery, J. W. Hodge, R. Newton, J. Schlom and K. Y. Tsang, Oncotarget, 2016, 7, 37762-37772.

27 A. Nayak-Kapoor, Z. Hao, R. Sadek, R. Dobbins, L. Marshall, N. N. Vahanian, W. Jay Ramsey, E. Kennedy, M. R. Mautino, 
C. J. Link, R. S. Lin, S. Royer-Joo, X. Liang, L. Salphati, K. M. Morrissey, S. Mahrus, B. McCall, A. Pirzkall, D. H. Munn, J. E. Janik and S. N. Khleif, J. Immunother. Cancer, 2018, 6, 61.

28 E. L. Raven, J. Biol. Inorg. Chem., 2017, 22, 175-183.

29 O. Hayaishi, S. Rothberg, A. H. Mehler and Y. Saito, J. Biol. Chem., 1957, 229, 889-896.

30 G. A. Hamilton, Adv. Enzymol. Relat. Areas Mol. Biol., 1969, 32, 55-96.

31 M. Sono, M. P. Roach, E. D. Coulter and J. H. Dawson, Chem. Rev., 1996, 96, 2841-2888.

32 A. C. Terentis, S. R. Thomas, O. Takikawa, T. K. Littlejohn, R. J. W. Truscott, R. S. Armstrong, S. R. Yeh and R. Stocker, J. Biol. Chem., 2002, 277, 15788-15794.

33 S. J. Thackray, C. G. Mowat and S. K. Chapman, Biochem. Soc. Trans., 2008, 36, 1120-1123.

34 G. Yagil, Tetrahedron, 1967, 23, 2855-2861.

35 S. J. Thackray, C. Bruckmann, J. L. R. Anderson, L. P. Campbell, R. Xiao, L. Zhao, C. G. Mowat, F. Forouhar, L. Tong and S. K. Chapman, Biochemistry, 2008, 47, 10677-10684.

36 N. Chauhan, S. J. Thackray, S. A. Rafice, G. Eaton, M. Lee, I. Efimov, J. Basran, P. R. Jenkins, C. G. Mowat, S. K. Chapman and E. L. Raven, J. Am. Chem. Soc., 2009, 131, 4186-4187.

37 C. Lu, Y. Lin and S.-R. Yeh, J. Am. Chem. Soc., 2009, 131, 12866-12867.

38 L. W. Chung, X. Li, H. Sugimoto, Y. Shiro and K. Morokuma, J. Am. Chem. Soc., 2008, 130, 12299-12309.

39 L. W. Chung, X. Li, H. Sugimoto, Y. Shiro and K. Morokuma, J. Am. Chem. Soc., 2010, 132, 11993-12005.

40 A. Lewis-Ballester, D. Batabyal, T. Egawa, C. Y. Lu, Y. Lin, M. A. Marti, L. Capece, D. A. Estrin and S. R. Yeh, Proc. Natl. Acad. Sci. U. S. A., 2009, 106, 17371-17376.

41 S. Yanagisawa, K. Yotsuya, Y. Hashiwaki, M. Horitani, H. Sugimoto, Y. Shiro, E. H. Appelman and T. Ogura, Chem. Lett., 2010, 39, 36-37.

42 R. M. Davydov, N. Chauhan, S. J. Thackray, J. L. R. Anderson, N. D. Papadopoulou, C. G. Mowat, S. K. Chapman, E. L. Raven and B. M. Hoffman, J. Am. Chem. Soc., 2010, 132, 5494-5500.

43 J. Basran, I. Efimov, N. Chauhan, S. J. Thackray, J. L. Krupa, G. Eaton, G. A. Griffith, C. G. Mowat, S. Handa and E. L. Raven, J. Am. Chem. Soc., 2011, 133, 16251-16257.

44 A. Lewis-Ballester, F. Forouhar, S.-M. Kim, S. Lew, Y. Wang, S. Karkashon, J. Seetharaman, D. Batabyal, B.-Y. Chiang, M. Hussain, M. A. Correia, S.-R. Yeh and L. Tong, Sci. Rep., 2016, 6, 35169-35182.

45 I. Efimov, J. Basran, S. J. Thackray, S. Handa, C. G. Mowat and E. L. Raven, Biochemistry, 2011, 50, 2717-2724.

46 T. Malcomson, K. Yelekci, M. Teresa Borrello, A. Ganesan, E. Semina, N. De Kimpe, S. Mangelinckx and R. R. Ramsay, FEBS J., 2015, 282, 3190-3198.
47 D. Griller and K. U. Ingold, Acc. Chem. Res., 1980, 13, 317-323.

48 M. Newcomb, Tetrahedron, 1993, 49, 1151-1176.

49 B. Roschek, K. A. Tallman, C. L. Rector, J. G. Gillmore, D. A. Pratt, C. Punta and N. A. Porter, J. Org. Chem., 2006, 71, 3527-3532.

50 M. Newcomb, C. C. Johnson, M. B. Manek and T. R. Varick, J. Am. Chem. Soc., 1992, 114, 10915-10921.

51 M. Newcomb, M. H. Le Tadic-Biadatti, D. L. Chestney, E. S. Roberts and P. F. Hollenberg, J. Am. Chem. Soc., 1995, 117, 12085-12091.

52 S. Y. Choi, P. E. Eaton, P. F. Hollenberg, K. E. Liu, S. J. Lippard, M. Newcomb, D. A. Putt, S. P. Upadhyaya and Y. Xiong, J. Am. Chem. Soc., 1996, 118, 6547-6555.

53 A. Lewis-Ballester, K. N. Pham, D. Batabyal, S. Karkashon, J. B. Bonanno, T. L. Poulos and S.-R. Yeh, Nat. Commun., 2017, 8, 1693.

54 D. Donati, A. Garzon-Aburbeh, B. Natalini, C. Marchioro and R. Pellicciari, Tetrahedron, 1996, 52, 9901-9908.

55 V. K. Aggarwal, E. Alonso, I. Bae, G. Hynd, K. M. Lydon, M. J. Palmer, M. Patel, M. Porcelloni, J. Richardson, R. A. Stenson, J. R. Studley, J.-L. Vasse and C. L. Winn, J. Am. Chem. Soc., 2003, 125, 10926-10940.

56 C. Zhu, J. Li, P. Chen, W. Wu, Y. Ren and H. Jiang, Org. Lett., 2016, 18, 1470-1473.

57 A. Blackburn, D. M. Bowles, T. T. Curran and H. Kim, Synth. Commun., 2012, 42, 1855-1863.

58 D. C. Horwell, M. J. McKiernan and S. Osborne, Tetrahedron Lett., 1998, 39, 8729-8732.

59 P. W. Blackby, M. de Kort, M. Enthoven, P. S. Hinchcliffe, C. Paulie, C. M. Timmers and S. Verkiak, NL. Pat., WO2013041458, 2013.

60 P. R. Reid, T. M. Bridges, D. J. Sheffler, H. P. Cho, L. M. Lewis, E. Days, J. S. Daniels, C. K. Jones, C. M. Niswender, C. D. Weaver, P. J. Conn, C. W. Lindsley and M. R. Wood, Bioorg. Med. Chem. Lett., 2011, 21, 2697-2701.

61 N. Chauhan, J. Basran, S. A. Rafice, I. Efimov, E. S. Millett, C. G. Mowat, P. C. E. Moody, S. Handa and E. L. Raven, FEBS J., 2012, 279, 4501-4509.

62 W. M. Kazmierski, B. Xia, J. Miller, M. De la Rosa, D. Favre, R. M. Dunham, Y. Washio, Z. Zhu, F. Wang, M. Mebrahtu, H. Deng, J. Basilla, L. Wang, G. Evindar, L. Fan, A. Olszewski, N. Prabhu, C. Davie, J. A. Messer,and and V. Samano, J. Med. Chem., 2020, 63(7), 3553-3562.

63 M. W. Pantoliano, E. C. Petrella, J. D. Kwasnoski, V. S. Lobanov, J. Myslik, E. Graf, T. Carver, E. Asel, B. A. Springer, P. Lane and F. R. Salemme, J. Biomol. Screening, 2001, 6, 429-440.

64 C. J. Layton and H. W. Hellinga, Biochemistry, 2010, 49, 10831-10841. 